\title{
小陇山国家自然保护区麻沿林区土壤肉鞭虫群落特征
}

\author{
邹 涛 ${ }^{1}$, 申海香 ${ }^{2}$, 马正学 ${ }^{3}$, 宁应之 ${ }^{3, *}$ \\ (1. 黄石理工学院, 湖北 黄石 435003; 2. 武威职业学院, 甘肃 武威 733000；3. 西北师范大学 生命科学学院, 甘肃 兰州 730070)
}

摘要: 2006 年 7 月 -2007 年 4 月, 用“非淹没培养皿法”和活体观察法对小陇山自然保护区麻沿林区土壤肉 鞭虫群落特征进行了研究。共鉴定到肉鞭类原生动物 78 种。其中包括 2 个未定名种和 12 个中国土壤肉鞭虫新纪 录种, 隶属于 2 亚门 5 纲 16 目 32 科 47 属。群落中变形目为优势类群, 动基体目和眼虫目为次优势类群, 腰鞭 目、领鞭目、源生目、双滴虫目和太阳目为偶见类群，小波豆虫、卵形波豆虫、气球屋滴虫和绿刺日虫为群落中 的优势种。结果表明, 小陇山麻沿林区土壤肉鞭虫物种丰富, 特有和稀有物种较多, 物种组成具有鲜明的独特性。

关键词：小陇山自然保护区；麻沿林区；土壤肉鞭虫；群落特征

中图分类号: Q958.15; Q959.113; Q959.114 文献标识码：Ａ 文章编号：0254-5853-(2009)05-0571-07

\section{Community Characteristics of Soil Sarcomastigophora in the Mayan Forest Region of the National Nature Reserve of Xiaolong Mountains}

\author{
ZOU Tao ${ }^{1}$, SHEN Hai-xiang ${ }^{2}$, MA Zheng-xue ${ }^{3}$, NING Ying-zhi ${ }^{3, *}$ \\ (1. Huangshi Institute of Technology, Huangshi 435003, China; 2. Wuwei Occupational College, Wuwei 733000, China; \\ 3. College of Life Sciences, Northwest Normal University, Lanzhou 730070, China)
}

\begin{abstract}
The community characteristics of soil Sarcomastigophora in the Mayan Forest Region of the National Nature Reserve of Xiaolong Mountains was studied using the "non-flooded petri dish method" and observation in vivo from July of 2006 to April of 2007. In total 78 species were identified, including 2 unnamed species and 12 new records of soil Sarcomastigophora in China, belonging to two subphylums, five classes, 16 orders, 32 families, and 47 genera. Amoebida was the dominant group, Kinetoplastida and Euglenida were the subdominant groups, Dinoflagellida, Chaenoflagellida, Pelobiontida, Diplomonaida and Actinophyrida were the incidental group, and Bodo minimus, Bodo ovatus, Oikomonas termo and Raphidiophrys viridis were the dominant species. The result of the study showed that there were abundant species and endemic and rare species in the community of soil Sarcomastigophora, the species composition of soil Sarcomastigophora in the Mayan Forest Region of the National Nature Reserve of Xiaolong Mountains was unique. The community characteristics of soil Sarcomastigophora was discussed based on analyzing the complexity and uniqueness of the ecological environment in the Mayan Forest Region of the National Nature Reserve of Xiaolong Mountains.
\end{abstract}

Key words: The National Nature Reserve of Xiaolong Mountains; The Mayan Forest Region; Soil Sarcomastigophora; Community characteristics

土壤肉鞭虫是土壤生态系统微型生物群落 (microbiota community)的重要组成部分, 不仅在土 壤生态系统的物质循环和能量流动中起着非常重 要的作用, 而且还能对某些土壤有害细菌和真菌起 到生物控制作用。此外，土壤肉鞭虫在土壤生态环 境评价中具有一定的生物指示和生物检测作用。
我国土壤肉鞭虫的研究起步较晚，始于 20 世 纪 80 年代(Cui, 1983)。较为系统的工作见于 Shen et al (1992); Ning \& Shen (1998b, c, 1999, 2000a, b ); Shen \& Ning (2000); Ning et al (2007a, b)。 这些系统的工作主要研究的是中国典型地带土壤 肉鞭虫的区系分布和分类，其中涉及西北地区的很 
少。西北地区占国土面积的 $32.20 \%$, 生态类型复杂 多样, 生物多样性十分丰富。而小陇山国家自然保 护区,地处中国南北分界线的秦岭山脉, 为华北、华 中、蒙新和喜马拉雅山植物交汇带, 在动物地理区 划上位于古北界与东洋界交接处的过渡带, 属于典 型的生物群落交错区, 具有重要的地理位置, 研究 其生物多样性十分必要。作者于 2006 年 7 月 -2007 年 4 月, 对小陇山自然保护区麻沿林区土壤肉鞭虫 群落进行了研究, 旨在比较系统地了解林区土壤肉 鞭虫的群落特征, 为土壤肉鞭虫在林区土壤生态系 统物质循环、能量流动及生物多样性维持机制中作 用的探讨，为林区生物资源的可持续利用及林区的 可持续发展提供基础资料, 也为我国土壤原生动物 的研究积累基础资料。

\section{1 研究地区与方法}

\section{1 研究地区自然概况}

麻沿林区位于小陇山国家级自然保护区内, 地 处秦岭南坡嘉陵江上游, 属徽县麻沿河乡境内。地 理位置为东经 $105^{\circ} 38^{\prime} \sim 105^{\circ} 39^{\prime}$, 北纬 $34^{\circ} 01^{\prime} \sim 34^{\circ} 02^{\prime}$, 海拔一般在 1400 1800 m之间。该林区包括麻沿、 杨坝、锁家坪、麻安、胡广、糜岭等 6 个营林区,
总面积 $30986 \mathrm{hm}^{2}$, 森林覆盖率为 $48.7 \%$ 。该林区 为亚热带过渡地区原始森林生态系统, 其动植物区 系分布呈现特殊的生物区系交汇系、组成成份的复 杂性和古老子遗性。保护区对改善我国西部地区环 境状况, 提高嘉陵江上游水源涵养具有非常重要的 保护意义和科学价值。

\section{2 采 样}

Sun et al（2005）将甘肃黄土高原分为 7 个气 候区: 陇中、陇东土壤严重缺水区, 陇中、陇东土 壤季节性缺水区，土壤水分适宜区，土壤水分湿润 区和甘南高原土壤水分湿润区。采样区位于土壤水 分适宜区内, 该区土壤水分适宜，在 $11 \% \sim 20 \%$ 之间。 耕作层土壤水分比较稳定, 在 $13 \%$ 以上无明显的土 壤缺水时段。浅层土壤水分从 5 月下旬到 10 月上 旬逐渐增加, 从 11 月上旬开始下降, 进入冬季失 墒期。

在林区内依据生境类型设置 6 个样区, 每个样 区再根据小生境设置采样点(图 1)。采样时测土壤温 度，采样方法见 Ning \& Shen（1998a）。

\section{3 样品预处理}

土样带回实验室后, 先测定土壤湿度、 $\mathrm{pH}$ 和 土壤含水率。湿度和 $\mathrm{pH}$ 的测定用 TSS-851 土壤湿

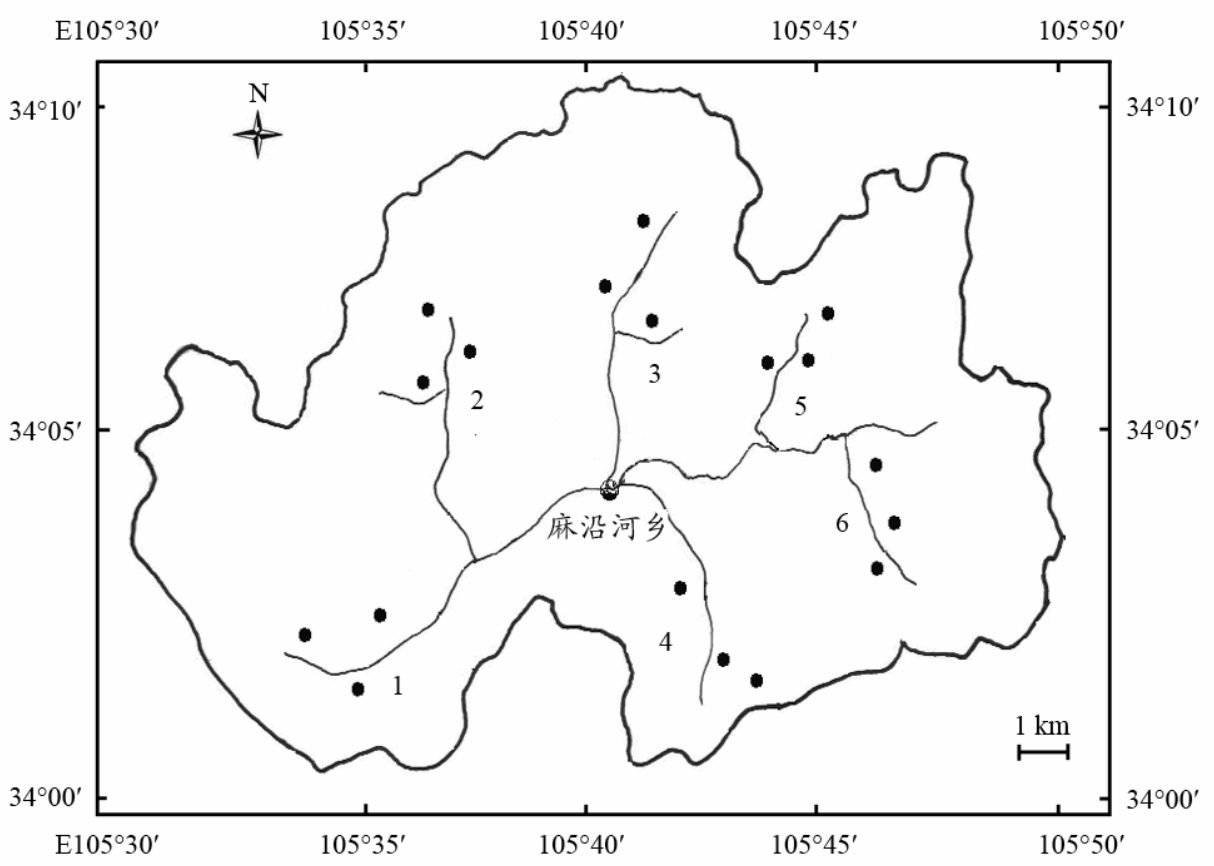

图 1 小陇山麻沿林区土壤肉鞭虫的采样点

Fig. 1 Sampling sites of soil Sarcomastigophora in the Mayan Forest Region of the National Nature Reserve of Xiaolong Mountains

1: 楸木沟(Qiumugou)；2：中滩沟(Zhongtangou)；3：杨家沟 (Yangjiagou)；4：爷殿山(Yedianshan);

5: 黑狐沟(Heihugou)； 6: 宽沟(Kuangou)。图中不规则形为麻沿林区 (Irregular-shaped figure the Mayan Forest Region)。 
度酸度计 (四平市电子技术研究所); 土壤含水率 的测定方法见 Wang (1998)。将实验土样倒入白瓷 盘中, 自然风干, 此过程需防止外界空气中的肉鞭 虫包囊进入土样中。

\section{4 培养和鉴定}

鞭毛虫的培养: 每份风干土样取 10 50 g 于培 养血中, 用“非淹没培养血法”(non-flooded petri dish method) (Foissner, 1992) 于光照培养箱中在 $25^{\circ} \mathrm{C}$ 恒温培养, 培养液为蒸馏水。每份土样重复培养若 干次, 直到未出现新见物种为止。

肉足虫采用两种方法进行培养: (1) 同鞭毛虫 的培养; (2) 配制三种培养液: $\mathrm{A}$ 液 $-\mathrm{CaCl}_{2} \cdot 2 \mathrm{H}_{2} \mathrm{O}$ $0.433 \mathrm{~g}+\mathrm{KCl} 0.162 \mathrm{~g}+100 \mathrm{~mL}$ 蒸馏水; $\mathrm{B}$ 液 $-\mathrm{K}_{2} \mathrm{HPO}_{4} 0.512 \mathrm{~g}+100 \mathrm{~mL}$ 蒸馏水; $\mathrm{C}$ 液 $-\mathrm{MgSO}_{4} \cdot 7 \mathrm{H}_{2} \mathrm{O} 0.28 \mathrm{~g}+100 \mathrm{~mL}$ 蒸馏水。称取 $1 \mathrm{~g}$ 莴 苣叶放入装有 $1000 \mathrm{~mL}$ 蒸馏水的容器中, 再分别加 入 $A 、 B 、 C$ 液各 $1 \mathrm{~mL}$ ，煮沸 $5 \mathrm{~min}$ ，过滤待用。取 滤液 $100 \mathrm{~mL}$ 加入 $1.5 \mathrm{~g}$ 琼脂, 在高压灭菌锅中灭菌 $30 \mathrm{~min}$ 后倾入培养血, 使之在培养血底呈一薄层(约 为培养血三分之一高度)。冷却后将琼脂划分为两 半, 一半均匀撒入 $5 \mathrm{~g}$ 风干土壤, 在土样上滴加蒸馏 水使之充分浸润; 另一半加少量土壤浸出液使之在 琼脂层上形成一薄层水膜, 置 $25^{\circ} \mathrm{C}$ 光照培养箱中恒 温培养 (Shen, 1992)。

培养后第 $4 \mathrm{~d}$ 开始镜检, 物种鉴定采用活体观 察法, 鉴定参考资料见参考文献 (Feng et al, 2004; Hu et al, 1980; Ning \& Shen, 1998a, b, 1999, 2000a, b; Shi et al, 1999; Shen et al, 1990; Bovee, 1985; Corliss, 1996; Decloitre, 1986; Foissner, 1994; Lee, 2000; Lynn, 1992; Ogden, 1983, 1984; Page, 1991; Patterson, 1991)。

\section{5 优势类群和优势种的划分群落相似性系数计} 算

对鉴定到的各级分类单元进行统计, 将物种数 最多和次多的目定义为优势类群和次优势类群, 将
单种的目定义为偶见类群。对培养 4 14d 各物种的 出现频次进行统计, 将出现频次最高的物种定义为 优势种。

用 Jaccard 相似性系数公式 $J=c /(a+b-c)$ 计算群 落相似性系数, 式中 $J$ 为相似性系数, $a 、 b 、 c$ 分 别为 $\mathrm{a}$ 地物种数、 $\mathrm{b}$ 地物种数和 $\mathrm{a} 、 \mathrm{~b}$ 两地共有物种 数。 $J$ 值在 $0 \sim 0.25$ 范围内为极不相似, 在 $0.25 \sim 0.5$ 范围内为中等不相似, 在 $0.5 \sim 0.75$ 范围内为中等相 似, 在 $0.75 \sim 1.0$ 范围内为极为相似。

\section{2 结 果}

\section{1 理化指标}

如表 1 所示, 从所测得的理化数据结果来看, 各样点的温度和 $\mathrm{pH}$ 变化不大, 但湿度和含水率变 化较大, 其幅度分别为 $7.7 \%$ 和 $17.6 \%$ 。各样点实际 测得的含水率明显高于该区土壤含水率范围。

\section{2 物种组成与群落结构}

在土样中共鉴定到肉鞭虫 78 种, 隶属于 2 亚 门 5 纲 16 目 32 科 47 属(表 3)。其中, 鞭毛亚门 (Mastigophora) 和肉足亚门 (Sarcodina) 分别为 41 和 37 种。在鞭毛亚门中, 植鞭纲 (Phytomastigophorea) 23 种, 占林区鞭毛虫物种 总数的 $56.10 \%$; 动鞭纲 (Zoomastigophorea) 18 种, 占 $43.90 \%$ 。在肉足亚门中叶足纲（Lobosea） 28 种, 占林区肉足虫物种总数的 $75.68 \%$; 丝足纲 (Filosea) 6 种, 占 $16.21 \%$; 太阳纲 (Heliozoea) 3 种, 占 $8.11 \%$ 。

林区土壤纤毛虫群落结构见表 3 。从表中可以 看出, 林区土壤肉鞭虫群落结构复杂, 计有 5 纲 16 目 32 科 47 属 78 种。叶足纲的物种最为丰富, 植 鞭毛纲、动鞭毛纲的物种次之, 网足纲和太阳纲的 物种相对较少。

从目级水平看, 群落中变形目 (Amoebida) 为 优势类群, 计有 21 种, 占肉鞭虫物种总数的 $26.92 \%$; 动基体目（Kinetoplastida）和眼虫目 (Euglenida) 为次优势类群, 各有 10 和 9 种, 分

表 1 小陇山自然保护区麻沿林区土壤理化数据

Tab. 1 Physicochemical properties of soil in the Mayan Forest Region of the National Nature Reserve of Xiaolong Mountains

\begin{tabular}{lcccccc}
\hline \multirow{2}{*}{\begin{tabular}{c} 
理化性质 \\
\cline { 2 - 7 } Physicochemical properties
\end{tabular}} & $\begin{array}{c}\text { 楸木沟 } \\
\text { Qiumugou }\end{array}$ & $\begin{array}{c}\text { 中滩沟 } \\
\text { Zhongtangou }\end{array}$ & $\begin{array}{c}\text { 杨家沟 } \\
\text { Yangjiagou }\end{array}$ & $\begin{array}{c}\text { 爷殿山 } \\
\text { Yedianshan }\end{array}$ & $\begin{array}{c}\text { 黑狐沟 } \\
\text { Heihugou }\end{array}$ & $\begin{array}{c}\text { 宽沟 } \\
\text { Kuangou }\end{array}$ \\
\hline 温度 Temperature $\left({ }^{\circ} \mathrm{C}\right)$ & 17.0 & 17.3 & 17.7 & 16.5 & 17.3 & 16.7 \\
湿度 Humidity (\%) & 37.0 & 29.3 & 32.7 & 35.3 & 35.3 & 32.7 \\
含水率 Moisture (\%) & 43.6 & 26.0 & 34.6 & 37.3 & 41.0 & 28.0 \\
$\mathrm{pH}$ & 7.1 & 7.2 & 7.0 & 7.1 & 7.1 & 7.0 \\
\hline
\end{tabular}


表 2 小陇山自然保护区麻沿林区土壤肉鞭虫物种

Tab. 2 Species of soil Sarcomastigophora in the Mayan Forest Region of the National Nature Reserve of Xiaolong Mountains

\begin{tabular}{|c|c|}
\hline 星状棘变形虫 Acanthamoeba astronyxis & 绿双鞭虫 Eutreptia viridis \\
\hline 月形刺胞虫Acanthocystis erinaceus ${ }^{*}$ & 奇观盖氏虫 Glaeseria mira \\
\hline 轴丝光球虫 Actinosphaerium eichhorni & 平截环滴虫 Goniomonas truncata \\
\hline 大变形虫 Amoeba proteus & 剑桥哈氏虫 Hartmannella cantabrigiensis \\
\hline 葡萄异鞭虫 Anisonema acinus & 易变小鞭虫 Mastigella commutans \\
\hline 右旋异鞭虫 A. dexiotaxum & 后湖马氏虫 $M$. hohuensis \\
\hline 广卵异鞭虫 A. prosgeobium & 扇形马氏虫 $M$. penardii \\
\hline 小漂眼虫 Astasia parvula & 柏马氏虫 $M$. cypressa \\
\hline 尾波豆虫 Bodo caudatus & 变形滴虫 Monas amoebina \\
\hline 梨波豆虫 B.edax & 延长滴虫 M. elongata \\
\hline 球波豆虫 B. globosus & 点滴虫 M. guttule \\
\hline 小波豆虫 B. minimus + & 小滴虫 M. minima \\
\hline 倒卵波豆虫 B. obovatus & 斜滴虫 M. oblique \\
\hline 卵形波豆虫 B.ovatus+ & 胡梨壳虫 Nebela barbata \\
\hline 慢行波豆虫 B. repens & 颈梨壳虫 N. collaris \\
\hline 可变波豆虫 B. variabilis & 小眼屋滴虫 Oikomonas ocellata \\
\hline 神使卡变虫 Cashia angelica & 气球屋滴虫 O. termo+ \\
\hline 飞燕角甲藻虫 Ceratium hirundinella ${ }^{*}$ & 象鼻㗜变形虫 Oscillosignum proboscidium \\
\hline 长尾尾滴虫 Cercomonas longicauda & 噬淀粉叶鞭虫 Phyllomitus amylophagus \\
\hline 放射尾滴虫 C. radiatus & 柔平变形虫 Platyamoeba placida \\
\hline 卵形尾滴虫 C. ovatus & 跳侧滴虫 Pleuromonas jaculans \\
\hline 简单尾滴虫 C.s simplex & 无恒多卓变虫 Polychaos dubium * \\
\hline 卡罗来纳卓变虫 Chaos carolinense ${ }^{*}$ & 束拟砂壳虫 Pseudodifflugia fascicularis \\
\hline 草履唇滴虫 Chilomonas paramaecium & 绿刺日虫 Raphidiophrys viridis + \\
\hline 小球衣滴虫 Chlamydomonas microsphaera & 鼻吻滴虫 Rhynchomonas nasuta \\
\hline 卵形衣滴虫 C. ovalis ${ }^{*}$ & 珊瑚囊变形虫 Saccamoeba gongornia \\
\hline 微小无吻虫 Clautriavia prava & 蛞蝓囊变形虫 Saccamoeba limax \\
\hline 啮蚀隐滴虫 Cryptomonas erosa & 明亮囊变形虫 S. lucens* \\
\hline 卵形隐滴虫 C. ovata & 条纹条纹变形虫 Striamoeba striata \\
\hline 宽口圆壳虫 Cyclopyxis eurostoma & 四线甲变形虫 Thecamoeba quadrilineata \\
\hline 坛状曲颈虫 Cyphoderia ampulla & 细粒管壳虫 Trachelomomas granulose \\
\hline 冠砂壳虫 Difflugia corona ${ }^{*}$ & 活泼雉滴虫 Trepomonas agilis \\
\hline 叉口砂壳虫 Difflugia gramen & 囊毛变形虫 Trichamoeba osseosaccus ${ }^{*}$ \\
\hline 斜形内管虫 Entosiphon obliquum & 线毛变形虫 $T$. vilosa \\
\hline 衣眼虫 Euglena chlamydophora* & 斜口三足虫 Trinema enchelys \\
\hline 棒形眼虫 Euglena clavata ${ }^{*}$ & 简简变虫 Vahlkampfia vahlkampfia \\
\hline 矛状鳞壳虫 Euglypha laevis & 贪婪简变虫 Vahlkampfia avara \\
\hline 鳞壳虫属一种 Euglypha sp. ${ }^{*}$ & 平足蒲变虫 Vannella platypodia \\
\hline 结节鳞壳虫 E. tuberculata & 杆变虫属一种 Vexillifera sp. \\
\hline
\end{tabular}

别占肉鞭虫物种总数的 $12.82 \%$ 和 $11.54 \%$; 腰鞭目 （Dinoflagellida）、领鞭目（Chaenoflagellida）、 泥生目 (Pelobiontida)、双滴虫目 (Diplomonaida) 和太阳目 (Actinophyrida) 为偶见类群。

小波豆虫 (Bodo minimu) 、卵形波豆虫 (Bodo ovatus) 、气球屋滴虫 (Oikomonas termo) 和绿刺 日虫 (Raphidiophrys viridis) 为群落中的优势种(表 2)。

\section{3 群落结构与环境因子的相关性}

应用 SPSS11.5 统计软件将环境因子（土温 T、 $\mathrm{pH}$ 、湿度 $\mathrm{H}$ 和含水量 $\mathrm{W}$ ) 与群落结构参数 (种类
数 NS）作为原变量, 进行二元变量的相关性分析, 得到表 4 。从表中可以看出: 种类数与土温, $\mathrm{pH}$ 之 间无显著相关性，而与湿度，含水量有显著正相关， 相关性系数分别为 $0.848 、 0.833$ 。依据相关性系数 的大小可知, 在各环境因子中, 对种类数影响最大 的是湿度, 其次是含水量。

\section{3 讨 论}

\section{1 林区土壤肉鞭虫物种丰富}

将小陇山自然保护区麻沿林区与我国 5 个典型 地带 9 个采样区一一海南尖峰岭、云南西双版纳、 
表 3 小陇山自然保护区麻沿林区土壤肉鞭虫群落结构

Tab. 3 Community structure of soil Sarcomastigophora in the Mayan Forest Region of the National Nature Reserve of Xiaolong Mountains

\begin{tabular}{|c|c|c|c|c|c|}
\hline 门 Phylum & 纲 Class & 目 Order & 科 Family & 属 Genera & 种 Species \\
\hline \multirow{16}{*}{$\begin{array}{l}\text { 肉鞭门 } \\
\text { Sarcomas-tigophora }\end{array}$} & \multirow{6}{*}{$\begin{array}{l}\text { 植鞭毛纲 } \\
\text { Phytomastigophorea }\end{array}$} & 隐滴虫目 Cryptomonadida & 2 & 2 & 4 \\
\hline & & 腰鞭目 Dinoflagellida & 1 & 1 & 1 \\
\hline & & 眼虫目 Euglenida & 5 & 6 & 9 \\
\hline & & 金滴虫目 Chrysomnadida & 1 & 2 & 7 \\
\hline & & 团虫目 Volvocida & 1 & 1 & 2 \\
\hline & & 领鞭目 Chaenoflagellida & 1 & 1 & 1 \\
\hline & \multirow{3}{*}{$\begin{array}{l}\text { 动鞭毛纲 } \\
\text { Zoomastigophorea }\end{array}$} & 动基体目 Kinetoplastida & 1 & 3 & 10 \\
\hline & & 泥生目 Pelobiontida & 1 & 1 & 1 \\
\hline & & 双滴虫目 Diplomonaida & 1 & 1 & 1 \\
\hline & & 分类地位未定 Uncertain taxonomic position & & 2 & 5 \\
\hline & \multirow{3}{*}{ 叶足纲 Lobosea } & 变形目 Amoebida & 8 & 16 & 21 \\
\hline & & 裂苂目 Schizopyrenida & 1 & 1 & 2 \\
\hline & & 表壳目 Arcellinida & 3 & 3 & 5 \\
\hline & 网足纲 Filosea & 网足目 Gromiida & 3 & 4 & 6 \\
\hline & \multirow{2}{*}{ 太阳纲 Heliozoea } & 太阳目 Actinophyrida & 1 & 1 & 1 \\
\hline & & 中阳目 Centrohelida & 2 & 2 & 2 \\
\hline Total & 5 & 16 & 32 & 47 & 78 \\
\hline
\end{tabular}

表 4 小陇山麻沿林区环境因子与土壤肉鞭虫群落结构参数的相关分析

Tab.4 The correlation analysis between environmental factors and structural parameters of ciliates community in the Mayan Forest Region of Xiaolong Mountains

\begin{tabular}{lcllr}
\hline & 土温 $\mathrm{T}$ & 湿度 $\mathrm{H}$ & 含水量 $\mathrm{W}$ & $\mathrm{pH}$ \\
\hline 种类数 $N \mathrm{~s}$ & -0.522 & $0.848^{*}$ & $0.833^{*}$ & -0.304 \\
皮儿逊相关系数 $r$ & 0.289 & 0.013 & 0.014 & 0.558 \\
\hline
\end{tabular}

${ }^{*} P<0.05$, 显著性相关。

湖南衡山、浙江西天目山、湖北神农架、湖北武昌 珞珈山、北京小龙门、吉林长白山和青海海北 (Ning \& Shen, 1998b, 2000a; Shen \& Ning, 2000 ), 以及 白水江自然保护区（表 5) 鉴定到的土壤肉鞭虫物 种数(Ning et al, 2007)进行比较可以得到如下结果: 白水江自然保护区 84 种 $>$ 小陇山自然保护区麻沿 林区 78 种 $>$ 湖南衡山 54 种 $>$ 浙江西天目山 51 种 $>$ 长白山 50 种 $>$ 北京小龙门 47 种 $>$ 西双版纳 42 种>青海海北 33 种>湖北珞珈山和海南尖峰岭 28 种>湖北神农架 24 种。结果表明, 小陇山自然保 护区麻沿林区土壤肉鞭虫物种除了比白水江自然 保护区的要少外, 比其他各采样区的都丰富。

\section{2 林区土壤肉鞭虫群落具有独特性}

在所鉴定到的 78 种土壤肉鞭虫中, 计有 2 个 未定名种和 12 个国内土壤肉鞭虫新纪录种(表 2)。 未定名种和新纪录种总计占肉鞭虫物种总数的 $17.95 \%$ ，表明林区内土壤肉鞭虫有较多的特有和稀 有物种。

根据 Jaccard 相似性系数公式计算得到小陇山 自然保护区麻沿林区与我国其他地区土壤肉鞭虫
群落的相似性系数(表 4)。林区与其他各地土壤肉鞭 虫群落的相似性系数均在 $0 \sim 0.25$ 范围内, 表明林区 与这些地区的土壤肉鞭虫群落均极不相似, 具有鲜 明的独特性。

动鞭类(Zooflagellates)中, 一些个体较小的种类 是“r”对策型原生动物。它们每天能繁殖几次, 最能 适应土壤生态系统, 在森林枯落层中数量最丰富

(Gao et al，2000)。在麻沿林区土壤中动鞭类种类 较丰富, 共鉴定到 18 种, 占土壤肉鞭类总数的 $23.08 \%$ ，其中小波豆虫、卵形波豆虫和气球屋滴虫 为群落中的优势种。裸变形虫类 (Amoebae) 具有 柔软的身体, 能够进入其它原生动物所不能达到的 微小土壤孔隙内, 因此在土壤中分布广泛 (Gao et al，2000)。在林区土壤中裸变形虫种类繁多，共鉴 定到 23 种, 占土壤肉鞭类总数的 $29.49 \%$ 。在有壳 类 (Testaceas) 中, Bonnet 根据壳的类型将其分为 4 类，即扁平状“表壳类”（Flattened“Arcella')、“顶 口壳类” (“Acrostome”) 、楔形“斜口壳类” ( Wedgeshaped'Plagiostome') 、球状 “中轴类” (Globose'axia')。形态类型在壳变形虫中的比例表 
表 5 小陇山自然保护区麻沿林区与中国其他地区土壤肉鞭虫群落的相似性

Tab. 5 Similarity between the community of soil Sarcomastigophora in the Mayan Forest Region of the National Nature Reserve of Xiaolong Mountains and in other areas of China

\begin{tabular}{|c|c|c|c|}
\hline 地区 Areas & $\begin{array}{l}\text { 物种数 } \\
\text { Number of species }\end{array}$ & $\begin{array}{c}\text { 与小陇山麻沿林区共有物种数 } \\
\text { Number of common species with the } \\
\text { Mayan Forest Region of Xiaolong } \\
\text { Mountains }\end{array}$ & $\begin{array}{c}\text { 相似性系数 } \\
\text { Ccefficient of similarity }\end{array}$ \\
\hline 浙江西天目山 Xitianmushan,Zhejiang & 51 & 19 & 0.147 \\
\hline 湖北武昌珞珈山 Luojiashan,Hubei & 28 & 15 & 0.142 \\
\hline 湖北神农架 Shennongjia,Hubei & 24 & 10 & 0.098 \\
\hline 北京小龙门 Xiaolongmen,Beijing & 47 & 19 & 0.152 \\
\hline 湖南衡山 Hengshan,Hunan & 54 & 16 & 0.121 \\
\hline 海南尖峰岭 Jianfengling,Hainan & 28 & 12 & 0.113 \\
\hline 吉林长白山 Changbaishan,Jilin & 50 & 21 & 0.164 \\
\hline 云南西双版纳 Xishuangbanna,Yunnan & 42 & 22 & 0.183 \\
\hline 青海海北 Haibei,Qinghai & 33 & 21 & 0.189 \\
\hline $\begin{array}{l}\text { 甘肃白水江自然保护区 } \\
\text { The National Nature Reserve of Baishuijiang,Gansu }\end{array}$ & 84 & 31 & 0.191 \\
\hline
\end{tabular}

*表中物种数来源于Ning \& Shen (1998b, 2000a); Shen \& Ning ( 2000 ); Ning et al (2007 )。

明了土壤的水分特征, 壳变形虫在干旱土壤中很 少，但在森林与苔原土壤中十分丰富（Bamforth， 1980 )。林区土壤中壳变形虫共有 11 种, 仅占肉鞭 虫物种总数的 $14.10 \%$ 。其中鳞壳虫属、砂壳虫属、 梨壳虫属等适宜在潮湿土壤和森林枯落物中生活 的种类较多, 而在干旱土壤中占优势的蛹壳虫属 (Corythion)、匣壳虫属 (Centropyxis)、法帽虫属 (Phryganella) 的种类在林区土壤中未鉴定到。

一般认为, 眼虫属和太阳虫属的种类是水生原 生动物。但两者在土壤中出现, 说明土壤含水量充 足 (Gao et al, 2000)。在林区土壤中鉴定到了眼虫 属的衣眼虫 (Euglena chlamydophora) 和棒形眼虫 (Euglena clavata) 两个种, 说明林区土壤含水量 较高, 这与实际测得的林区土壤湿度和含水率相一 致。

在林区土壤中还鉴定到马氏虫属（Mayorella） 的 3 个种一一后湖马氏虫 (M. hohuensis)、扇形马 氏虫 (M. penardi) 和柏马氏虫 (M. cypressa)。一 般认为, 马氏虫属的种类在土壤中没有分布, 因为 它们不能形成包囊 (Foissner, 1987)。土壤原生动 物在生理学上的适应性除形成包囊外, 还有一种处 于间生态的适应现象 (Foissner, 1987)，马氏虫属

\section{参考文献:}

Bamforth SS. 1980. Terrestrial protozoa[J]. Prozool, 27(1):33-36.

Bovee EC. 1985. The lobose amebas III. Descriptions of nine new conopodous amebas of the genus Vexillifera Schaeffer, 1926, emend. Bovee 1951, 1970, with comment on the genus[J]. Arch Protistenk, 129: 101-118.
的种类虽不能形成包囊，但很有可能存在间生态的 适应现象, 因而也能在土壤中生存。而 Ning et al (2007)、Feng et al (2004)、Chen et al (2003)、 Ma et al (2002) 也在土壤中鉴定到马氏虫, 说明马 氏虫属的种类确能在土壤中生存。

\section{3 群落特征与林区生态环境的关系}

生态环境的复杂性是生物群落复杂性和独特 性的基础。采样区的植被类型、调落物层厚度、水 热条件、土壤类型、土壤理化特征以及地形、坡向、 坡度等具体小环境条件的差异对肉鞭虫在土壤的 分布有或多或少的影响。其中, 某些因素还有可能 是主要影响因素（Ning，1996）。特别是土壤微域 环境中的含水量、温度、酸碱性对土壤肉鞭虫的影 响尤为突出。如果水分蒸发, 会导致土壤溶液变浓 和渗透压增大, 当降水量增多时会造成厌氧环境, 因此, 土壤水分是影响土壤肉鞭虫生存的重要因 子。本文结果也证明了这一点。

致谢: 本次调查的采样工作得到了西北师范大 学生命科学学院 2005 级研究生王娟、惠继瑞, 2004 级本科生严谨、冯强生、陈明忠等同学的大力帮助, 在此向他们致以诚挚的谢意。

Corliss JO. 1996. Protozoology [M]. 2nd ed. New York: Thieme Medical Publishers Inc, 1-338.

Chen SF, Xu RL, Wang YJ, Zan QJ, Liao WB. 2003. Effect of chemical prevention and cure of Mikania Micrantha on soil protozoan community in Neilingding Island [J]. Chn J Appl Environ Biol 9(4): 
422-428. [陈素芳, 徐润林, 王勇军, 各启杰, 廖文波. 2003. 化学防 除薇甘菊对内伶仃岛土壤原生动物群落的影响. 应用与环境生物 学报, 9(4): 422-428.]

Cui ZD. 1986. Ecological distribution of soil protozoa under coniferous-broad leaved mixed forest in Northern Slope of Changbai Mountain[J]. Chn J Ecol, 5(2): 3-7. [崔振东. 1986. 长白山北坡针阔 混交林土壤原生动物的生态分布. 生态学杂志, 5(2): 3-7.]

Decloitre L. 1986. Compléments aux publications précédents Mise à jour au 31. XII.1984 des genres Arcella, Centropyxis, Cyclopyxis, Euglypha et Nebela[J]. Arch Protistenk, 132: 131-136.

Ekelund F, Rönn R. 1994. Notes on protozoa in agricultural soil with emphasis on heterotrophic flagellate and naked amoebae and their ecology [J]. FEMS Microbiol Rev, 15: 321-353.

Feng WS, Yang J, Ye ZH, Miao W, Yu YH, Huang MH, Shen YF. 2004. Soil protozoa in wetland treatment system of $\mathrm{Pb}-\mathrm{Zn}$ mine in Fanko[J]. Chn $J$ Zool, 39(1): 2-11. [冯伟松, 杨 军, 叶志鸿, 缪 伟, 余育和, 黄 铭洪, 沈暳芬. 2004. 凡口铅锌矿湿地处理系统的土壤原生动物. 动物学杂志, 39(1): 2-11.]

Foissner W. 1987. Soil protozoa: fundamental problems, ecological significance, adaptations in ciliates and testaceans, bioindicators, and guide to the Literature[J]. Prog Protistol, 2: 69-212.

Foissner W. 1992. Estimating the Species Richness of Soil Protozoa Using the"Non-Fooded Petri Dish Method"[M// Lee JJ, Soldo AT. Protocols in Protozoology. Lawrence: Allen Press, B-10.1-B-10.2.

Foissner W. 1994. Die Urtiere (Protozoen) des Bodens[J]. Kataloge des OÖ Landesmuseums $N F$, 71: 169-218.

Gao YC, Zhu WS, Chen WX. 2000. Structure of the protozoan community in soil and its ecological functions [J]. Chn J Ecol, 19(1): 59-65. [高云 超, 朱文珊, 陈文新. 2000. 土壤原生动物群落及其生态功能. 生态 学杂志, 19 (1): 59-65.]

Hu HJ, Li YY, Wei YX, Zhu HZ,Chen JY,Shi ZX. 1980. Freshwater Algae in China[M]. Shanghai: Science Technology Press, 1-525. [胡鸿钧, 李 尧英, 魏印心, 朱蕙忠, 陈嘉佑, 施之新. 1980. 中国淡水藻类. 上 海: 上海科学技术出版社, 1-525.]

Lee JJ, Leedale GF, Bradbury P. 2000. An Illustrated Guide to the Protozoa: Volume I, Volume II. [M]. 2nd ed. Lawrence: Allen Press , 1-743.

Lynn M, Heather IM, Lorraine O. 1992. Illustrated Glossary of Protoctista [M]. London: Jones and Bartlett Publishers, 137-288.

Ma ZX, Gong DJ, Ning YZ, Niu SQ, Liu ZJ, Cui YD. 2002. Studies on the effect to soil pollution by waste material of Lead and Zincore mining on protozoa[J]. J Gansu Sci, 14(3): 53-57. [马正学, 輁大洁, 宁应之, 牛世全, 刘左军, 崔永德. 2002. 铅锌矿采矿废物污染对土壤原生 动物的影响. 甘肃科学学报, 14(3): 53-57.]

Ning YZ, Li QL, Li XH, Ma ZX, Mao JP, Liu K, Bai XM. 2007. Specific diversity of soil amoebae and flagellates in the Nationa Nature Reserve of Baishuijiang, Gansu[J]. Chn J Zool 42(4): 81-88. [宁应之, 李琦路, 李晓鸿, 马正学, 毛金平, 刘 恺, 白雪梅. 2007. 甘肃白水江国家 级自然保护区土壤肉鞭虫物种多样性. 动物学杂志, 42(4): 81-88.]

Ning YZ, Shen YF. 1996. Ecological studies on the forest soil protozoa of Mount Luojiashan and exploration of quantitative methods for soil protozoa [J]. Zool Res, 17(3): 225-232. [宁应之, 沈暳芬. 1996. 珞珈 山森林土壤原生动物生态学研究及土壤原生动物定量方法探讨. 动物学研究, 17(3): 225-232.]

Ning YZ, Shen YF. 1998a. Collection of soil protozoa[M]// The Writing Group of A Handbook for the Research Methods of Soil Animals. A Handbook for the Research Methods of Soil Animals. Beijing: Chinese Forestry Publishing House, 56-57. [宁应之, 沈暳芬. 1998a. 土壤原生 动物的采集. 土壤动物研究方法手册编写组, 土壤动物研究方法手 册. 北京: 中国林业出版社, 56-57.]
Ning YZ, Shen YF. 1998b. Soil protozoa in typical zones of China: I. Faunal characteristics and distribution of species[J]. Acta Zool Sin, 44(1): 5-10 .[宁应之, 沈暳芬. 1998b. 中国典型地带土壤原生动物: I. 区 系特征和物种分布. 动物学报, 44(1): 5-10.]

Ning YZ, Shen YF. 1998c. Soil protozoa in typical zones of China: II. Ecological study[J]. Acta Zool Sin, 44(3): 271-276.[宁应之, 沈暳芬. 1998c. 中国典型地带土壤原生动物: II. 生态学研究. 动物学报, 44(3): 271-276.]

Ning YZ, Shen YF. 1999. Species of protozoa first recorded in Chinese soils (Sarcomastigophora) [J]. Chn J Zool, 34(6): 2-5.[宁应之, 沈暳芬. 1999. 中国土壤原生动物新记录种(肉鞭虫门). 动物学杂志, 34(4): 2-5.]

Ning YZ, Shen YF. 2000a. Faunal characteristics of soil protozoa [M].//: Yin WY, Zhang RZ, Yin SG. Soil Animals of China . Beijing: Science Press, 209-220. [宁应之, 沈暳芬. 2000a. 土壤原生动物区系特点. 尹文英, 张荣祖, 殷绥公. 中国土壤动物. 北京: 科学出版社, 209-220.]

Ning YZ, Shen YF. 2000b. On the ecology of soil protozoa [M]//Yin WY, Zhang RZ, Yin SG. Soil Animals of China. Beijing: Science Press, 134-149. [宁应之, 沈暳芬. 2000b. 土壤原生动物生态. 尹文英, 张 荣祖, 殷绥公. 中国土壤动物. 北京: 科学出版社, 134-149.]

Ning YZ, Wang J, Liu N, Ma ZX. 2007b. Community characteristics of soil sarcodinids and flagellates in the Scenic Spots and Historic Sites of Maijishan, Gansu [J]. Acta Ecol Sci, 27(11): 4469-4477.[宁应之, 王 娟, 刘 娜, 马正学. 2007b. 甘肃天水麦积山风景名胜区土壤肉鞭 虫群落特征. 生态学报, 27(11): 4469-4477.]

Ogden CG. 1984. Note on testate amoebae (Rhizopodea, Protozoa) form Lake Vlasina, Yugoslavia[J]. Bull Br Mus Nat Hist Zool, 47(5): 241-263.

Page FC, Siemensma FJ. 1991. Nackte Rhizopoda und Heliozoea [M]. Stuttgart: Gustav Fischer Verlag, 1-297.

Patterson DJ, Larsen J. 1991. The Biology of Free-living Heterotrophic Flagellates[M]. Oxford: Oxford University Press, 1-502.

Shen YF. 1992. Quanlitative methods for soil protozoa[M]// Yin WY, Yang FC, Wang ZZ. Subtropical Soil Animals of China. Beijing: Science Press, 85-86. [沈暳芬. 1992. 定性方法. 尹文英, 杨逢春, 王振中 中国亚热带土壤动物. 北京: 科学出版社, 85-86.]

Shen YF, Ning YZ. 2000. Protozoa [M]// Yin WY. Pictorial Keys to Soil Animals of China. Beijing: Science Press, 7-42, 393-427.

Shen YF, Zhang ZS, Gong XZ, Gu MR, Shi ZX, Wei YX. 1990. Modern biomonitoring techniques using freshwater microbiota[M]. Beijing: Chinese Architecture and Building Press, 231-524. [沈暳芬, 张宗涉, 龚循矩, 顾曼如, 施之新, 魏印心. 1990. 微型生物监测新技术. 北 京: 中国建筑工业出版社, 231-524.]

Shi ZX, Wang QX, Xie SL,Dai JS,Chen LQ. 1999. Freshwater algae in China: Tomus VI, Euglenophyta[M]. Beijing: Science Press, 1-414.[施 之新, 王全喜, 谢树莲,戴健寿,陈立群. 1990. 中国淡水藻志 : 第 6 卷:裸藻门) 北京: 科学出版社, 1-414.]

Sun BQ, Zhang Q, Dong AX, Chen SY. 2005. Evolution feature on the moisture of soil for Loess Highland in Gansu[J]. Adv Earth Sci, 20(9): 1041-1045. [孙秉强, 张强, 董安祥, 陈少勇. 2005. 甘肃黄土高原 土壤水分气候特征. 地球科学进展, 20(9): 1041-1045.]

Wang ZZ. 1998. Selection of sample site[M]// The Writing Group of A Handbook for the Research Methods of Soil Animals. A Handbook for the Research Methods of Soil Animals. Beijing: Chinese Forestry Publishing House, 87-91. [王振中. 1998. 样地选择. 土壤动物研究方 法手册编写组. 土壤动物研究方法手册. 北京: 中国林业出版社, 87-91.] 